\title{
The Effect of Substrate Temperature on The Band Transition ,Cauchy Dispersion and Urbach Energy of Nanostructure CdO Thin Films
}

\author{
Muneer H. Jadduaa ${ }^{1}$, Zainab Ali Harbi ${ }^{1}$, Nadir F. Habubi ${ }^{2}$, \\ ${ }^{1}$ College of Science, Wasit University, Wasit, Iraq \\ ${ }^{2}$ College of Education, Al-Mustansiriyah University, Baghdad, Iraq \\ "Corresponding author E-mail address: nadirfadhil@uomustansiriyah.edu.iq
}

Keywords: CdO thin films, Cauchy dispersion relation, Urbach energy ,CSP

\begin{abstract}
Thin films of CdO were prepared by chemical spray pyrolysis (CSP) . The effect of different temperature substrate $(300,350,400,450$ and 500$){ }^{\circ} \mathrm{C}$ on some optical parameters has been studied. The transmittance and the optical energy gap were increased from (2.503-2.589) eV ,on the contrary of the rest parameters such as refractive index, real and imaginary parts of dielectric constant and Urbach energy which they were decreased as the substrate temperature increase.
\end{abstract}

\section{INTRODUCTION}

Transparent conducting oxides (TCOs) have been acquired huge importance in many research fields due to their unique properties such as their: high transparency, wide band energy gap and distinct electrical properties [1.2]. Cdo was one of the most candidate material suitable for many industrial applications like, window layer [3], solar cell [4], photovoltaic cell [5],photodector [6], gas sensor [7,8] and in optical communications [9] .

Previously in the literature, there are scarce papers concerning the effect of substrate temperature by CSP. Ali (2014) [10] studied the effect of substrate temperature $(350,400,450)^{\circ} \mathrm{C}$ for Cdo thin films prepared by chemical spray pyrolysis from an aqueous solution of cadmium chloride,she calculated the average crystallite size and the optical energy gap of the as deposited film and found to be in the range of $(11-37) \mathrm{nm}(2.4-2.5) \mathrm{eV}$ respectively as the substrate temperature increase. Nadir et al. (2015) [11] study the effect of substrate temperature $(300,350,400,450 \text { and } 500)^{\circ} \mathrm{C}$ prepared by spray pyrolysis from an aqueous solution of Cadmium acetate, the XRD pattern indicates that the average crystallite size was in the range of (17-25) $\mathrm{nm}$ as the substrate temperature increase .AFM reveal that the average diameter were in the range of nano scale confirmed the existence of nanostructure.

The aim of this work is to continue what has been done by Nadir et al. and study the effect of substrate temperature upon kind electronic transitions,optical energy gap, refractive index obtained by cauchy's dispersion, real and imaginary parts of the dielectric constant and, finally Urbach energy,

$\mathrm{CdO}$ thin films were prepared onto glass substrates by chemical spray pyrolysis technique . The substrate was subjected to clean process inception from rinse with re-distilled water, placed in an ultrasonic bath filled with ethanol absolute, dunk in acetone and finally rinse with re-distilled water, dried with hot air. An aqueous solution of $0.1 \mathrm{M} \mathrm{Cd}\left(\mathrm{CH}_{3} \mathrm{COO}\right)_{2} \cdot 2 \mathrm{H}_{2} \mathrm{O}$ dissolve in $100 \mathrm{ml} \mathrm{re}-$ distilled water, were used as a source of cadmium.

The optimum preparing conditions can be summerized by the following: the substrate temperature was varied from $\left(300-500{ }^{\circ} \mathrm{C}\right)$, distance between nozzle and substrate was kept at $30 \mathrm{~cm}$, spray rate was $5 \mathrm{ml} / \mathrm{min}$, spray time was fixed at $9 \mathrm{~s}$ followed by $90 \mathrm{~s}$ waiting to avoid excessive cooling and to prevent glass cracking, during waiting the samples were rotated at the heater in order to obtain a homogeneous films and the nitrogen atmosphere into the chamber was operated at a flow rate of $6 \mathrm{x}$ $10^{3} \mathrm{~cm}^{3} / \mathrm{min}$.

The film thickness was obtained by gravimetric method and their values was around $250 \pm 25 \mathrm{~nm}$. Optical measurments were carried out using a double beam spectrophotometer supplied by (Schimadzu UV probe 1650 Japan) in the wavelength range (300-900) nm.[11] 


\section{RESULTS AND DISCUSSION}

Fig. 1 depicts the transmission spectra of the deposited thin films at different substrate temperature. It can be clearly seen that the transmittance from wavelengths of (550-900) nm are improved by the increase in substrate temperature, this behavior agree with Abd et al.[12]. The low transmittance may be attributed to the defect state and lattice imperfection . We can see from the graph that the transmittance shows a steed change in their at lower wavelengths and, the absorption band was shifted toward short wavelength (blue shift) .

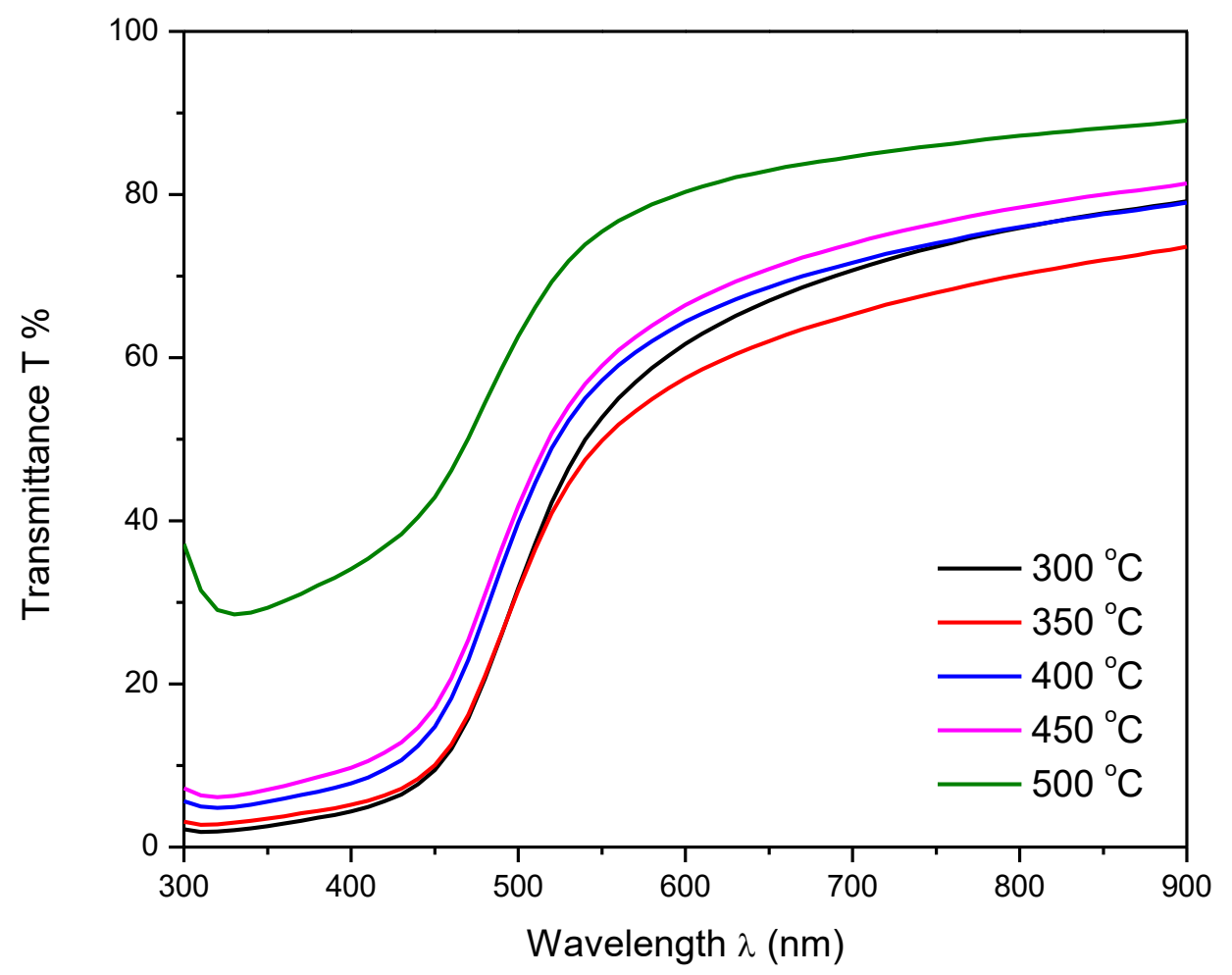

Fig. 1 Transmittance spectra of $\mathrm{CdO}$ with different substrate temperature

The optical energy gap for direct allowed transition was estimated from the well known relation introduced by Tauc [13]. The plot of $(\alpha h v)^{2}$ versus photon energy is shown in Fig. 2 for the deposited films with different substrate temperature, energy gap was determined from extrapolation of straight line portion of the curve to x-axis (photon energy) as can be seen from the results, the optical energy gap increased with the increasing in substrate temperature. 

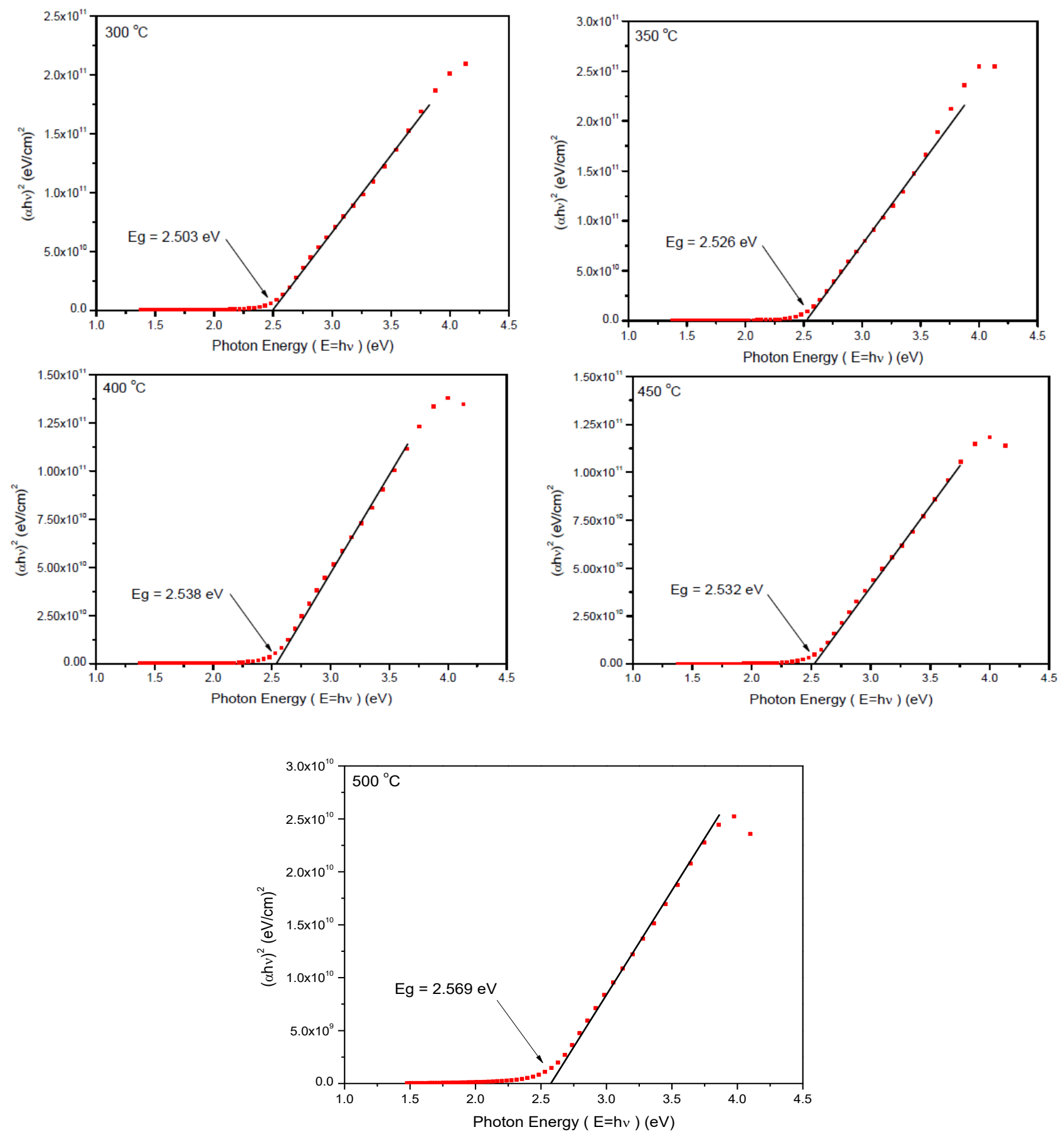

Fig.2 $(\alpha h v)^{2}$ versus photon energy for different substrate temperature

The value of refractive index $n_{o}$ can be fitted to two term Cauchy dispersion formula [14] as seen if Fig. 3 which confirmed that the refractive index decrease as the substrate temperature increase.

The real and imaginary parts of dielectric constant are related to the refractive index $n_{o}$ and extinction coefficient $\mathrm{k}_{\mathrm{o}}$ by the relation [15]

$$
\begin{aligned}
& \epsilon_{r}=n_{o}^{2}-k_{o}^{2} \\
& \epsilon_{i}=2 n_{o} k_{o}
\end{aligned}
$$

The value of the real and imaginary parts are shown in Fig 4a and Fig. 4b. The real and imaginary parts exhibit the same behavior that their values was decreased as the substrate temperature increase, $\epsilon_{r}$ was higher than $\epsilon_{i}$. 
The Urbach energy of the deposited films can be estimated using the following relation [16]:

$$
\alpha=\alpha_{o} \exp \left(\frac{h v}{E_{U}}\right)
$$

where $h v$ is the incident photon energy, $\alpha_{o}$ is constant, $E_{U}$ is the Urbach energy which is related to the width of the exponential absorption edge. The plot of $\ln (\alpha)$ versus photon energy was shown in Fig. 5 . Urbach energy was calculated fro the inverse gradient of the linear portion and from this Fig we can see that their values were decrease as the substrate temperature increase, this is might be due to the relation between Urbach energy and optical energy gap which must take the inverse behavior
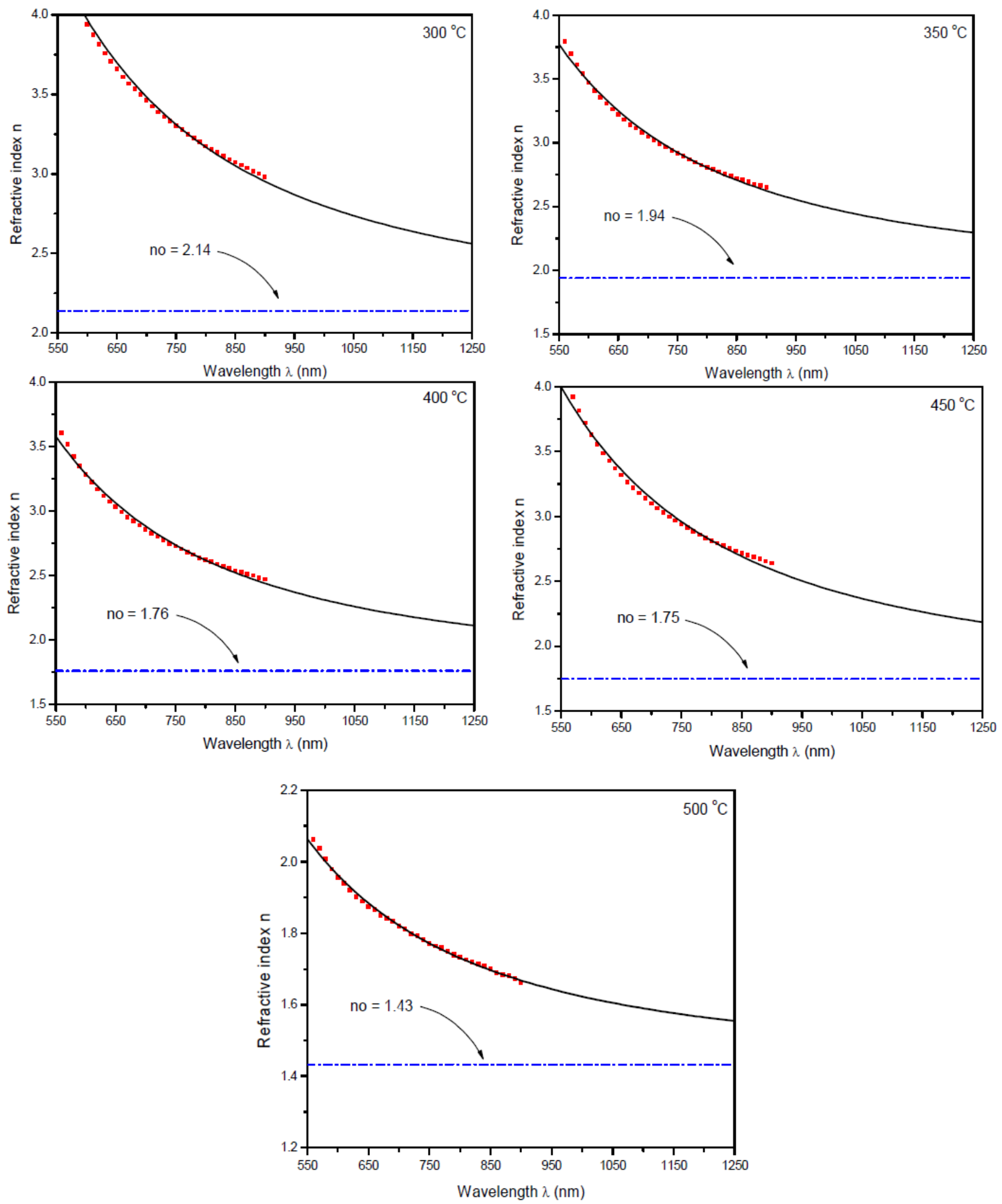

Fig. 3 Refractive index versus wavelength for different substrate temperature 


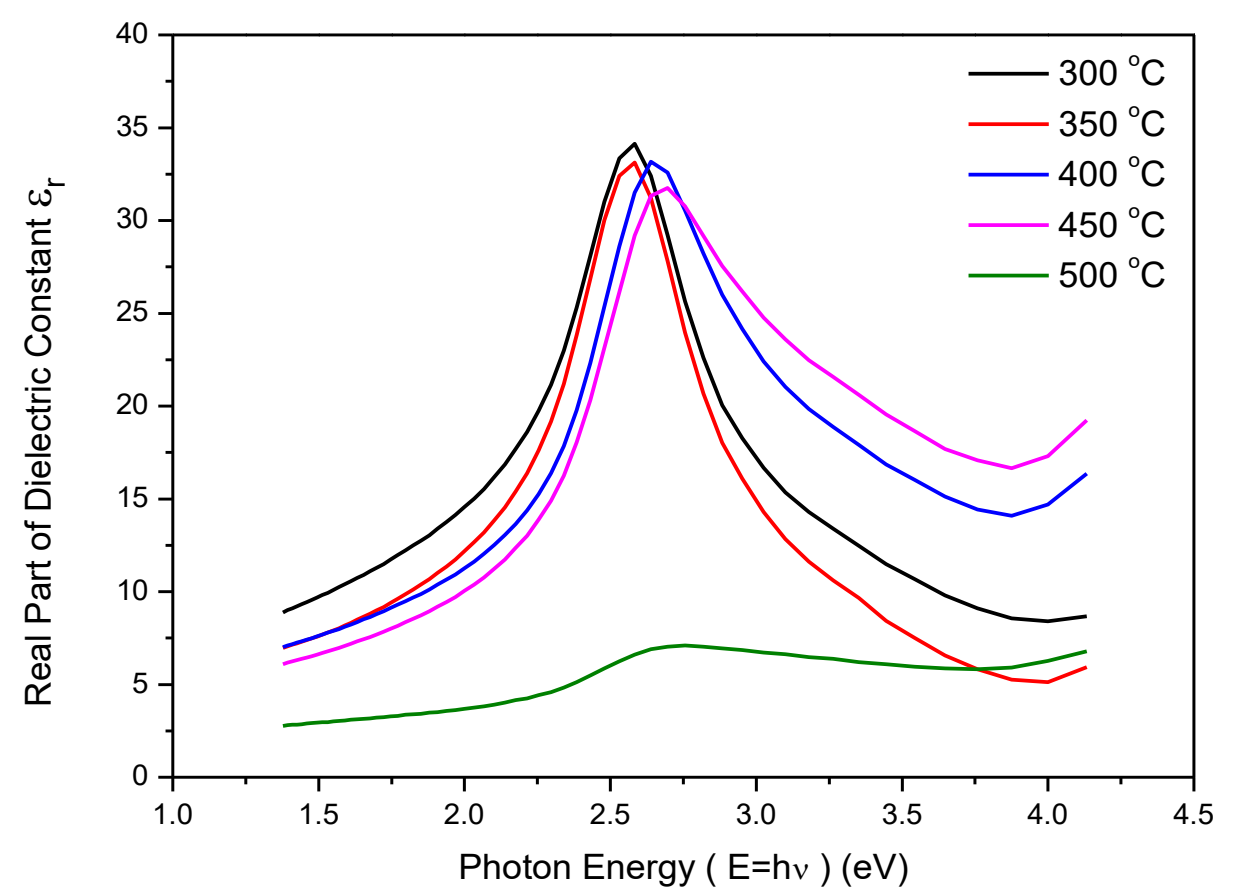

(a)

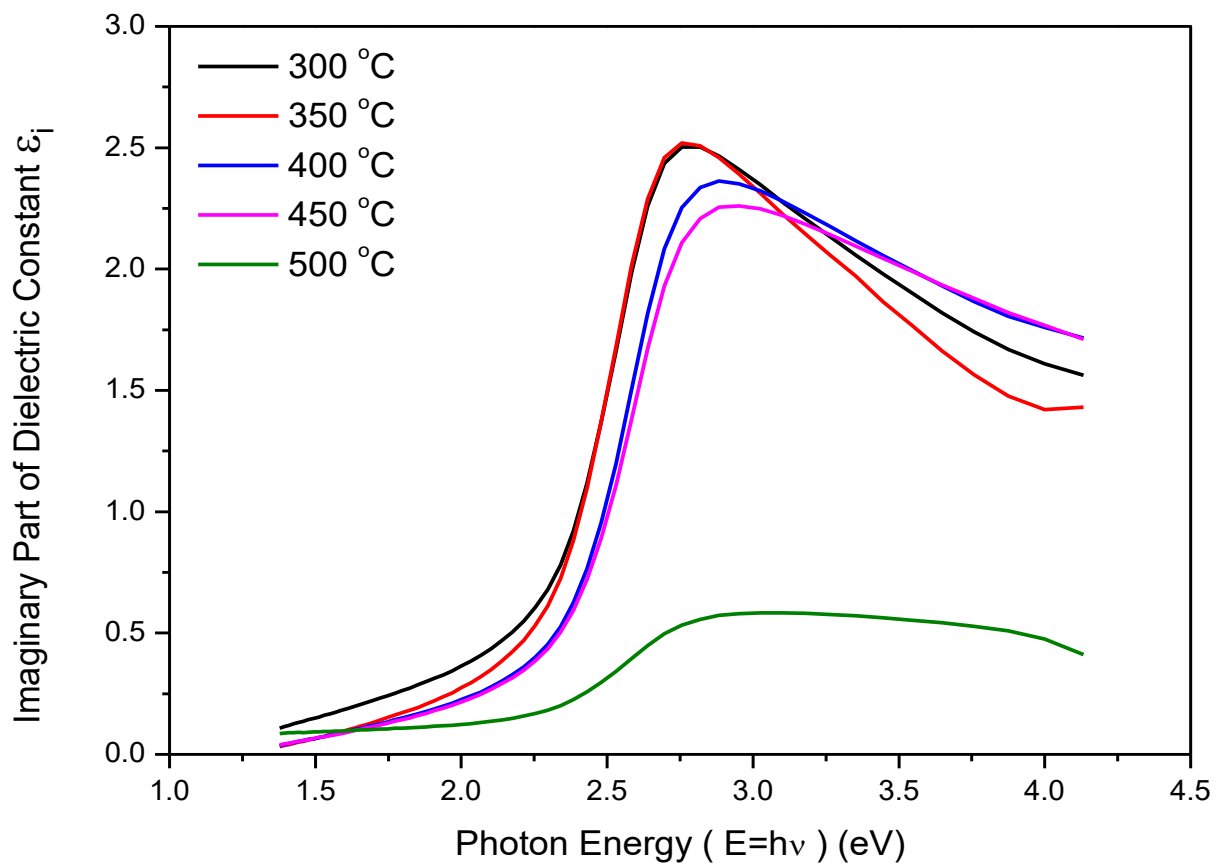

(b)

Fig. 4 Real (a) and Imaginary (b) parts of dielectric constant for different substrate temperature 

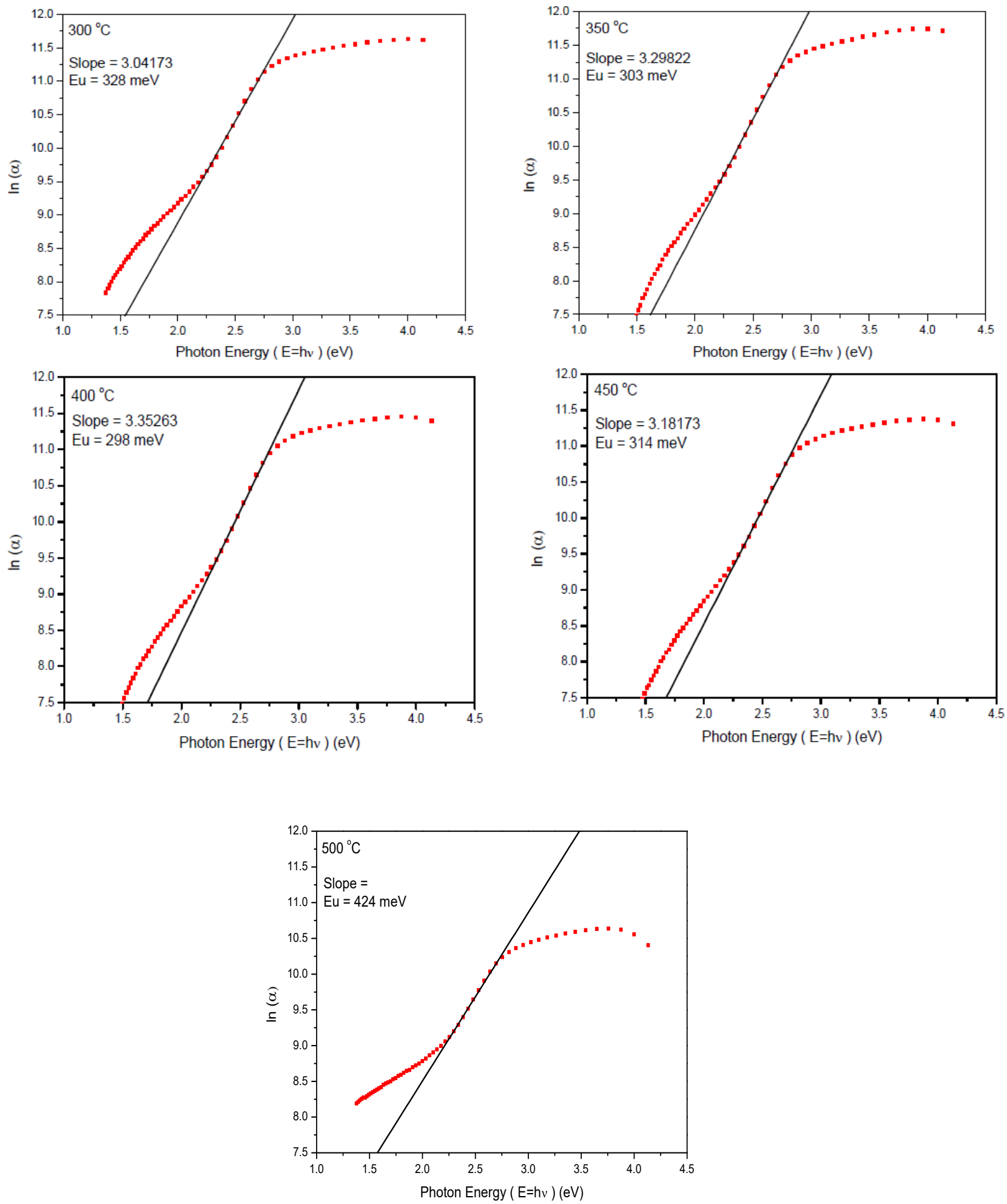

Fig. 5 Urbach energy versus photon energy of different substrate temperature

\section{CONCLUSIONS}

The $\mathrm{CdO}$ was prepared successfully utilizing chemical spray pyrolysis technique.The raise of substrate temperature improves the transmittance and increase the optical energy gap which,its value was higher than its bulk value due to quantum confinement of the nanostructure $\mathrm{CdO}$ thin films. The refractive index estimated from Cauchy's dispersion relation confirmed that their value decrease as the substrate temperature increase. The value of Urbach energy was decreased to assure that the defects and tails were decreasing as the substrate temperature increase. 


\section{References}

[1]- K. Kesavan ,V. Manivannan, and R. Ramads Nano Vision 3(2013)209.

[2]- S. Aksoy, Y. Caglar World Academy of Science \&Technology 59(2011)2113.

[3]- A. A. Al-Quraini Photovoltaic Conference 26 IEEE (1997)415.

[4]- Raid A. Ismail ,Omar A. Abdulrazaq Solar Enegry Materials \& Solar Cells 91(2007)903.

[5]- C. H. Champness, K. Ghoneim, J.K. Chem Candian Journal of Physics 63(1985)676.

[6]- M. Ortega ,G, Santana , A.Merales-Acevedo Solid State Electronics 44(2000)1765.

[7]- R. H. Bari ,S. B. Patil International Letters of Chemistry, Physics and Astronomy 37(2014)31.

[8]- R. Ferro , J. A. Rodriguez ,I Jimenez, A. Cirera, J. Cerada,J. R. Morante IEEE Sensor Journal 5 (2005) 48.

[9]- A. A. Dakel Optical Materials 31(2009)691.

[10]- Hanan R. A. Ali International Letters of Chemistry, Physics and Astronomy 8 (2014) 47.

[11]- Nadir F. Habubi, Muneer H. Jadduaa, Zainab Ali Harbi World Scientific News12(2015)19.

[12]- J. A. Abd,E.M. Al-Robay,Z. J, Shanan,Nadir F. Habubi Journal of Advance in Chemistry11(2015)3475.

[13]- J. Tauc, R. Grigorvici, Y. Yanca, Phys. Status Solidi 15 (1966) 627.

[14]- A. M. Nasr , H. I. Abd El-kader, M. Farhat Thin Solid Films 515(2006)1758.

[15]- J. N. HODGSON, Optical Absorption and Dispersion in Solids, Chapman and Hall, 1970.

[16]- F. Urbach, Phys. Rev. 92 (1953) 1324. 